\title{
O FENÔMENO RELIGIOSO EM HUME: NATURALISMO E CETICISMO
}

\author{
THE RELIGIOUS PHENOMENON IN HUME: NATURALISM AND SKEPTICISM
}

\author{
Crysman Dutra* \\ Cleiton F. D. Barbosa** \\ Andreza C. D. Barbosa ${ }^{* * *}$
}

\section{RESUMO}

Nosso artigo se divide em três partes. Na primeira vamos apresentar os problemas epistemológicos que Hume considera dignos de tratamento filosófico. A segunda parte aborda a dimensão fenomenológica das crenças religiosas, trata-se dos processos de formação de crenças religiosas. A terceira e última parte apresenta as críticas de Hume que rechaçam o argumento do desígnio, que se encontram explicitamente formuladas no Diálogo sobre as Religiões Natural ${ }^{1}$, obra publicada postumamente.

PALAVRAS-CHAVE: Hume. Religião. Naturalismo. Ceticismo.

\begin{abstract}
Our article is divided into three parts. In the first one we will present the epistemological problems that Hume considers worthy of philosophical treatment. The second part deals with the naturalistic dimension of religious beliefs, the processes of formation of religious beliefs. The third and final chapter presents Hume's skeptical criticisms, which are explicitly formulated in the Dialogue on Natural Religions, a work published posthumously.
\end{abstract}

KEYWORDS: Hume. Religion. Naturalism. Skepticism.

\section{INTRODUÇÃO}

Publicada em 1757, a História natural da religião $o^{2}$ é considerada por vários estudiosos do tema a primeira obra a tratar as crenças religiosas de modo naturalista, desprovida de uma metafísica teleológica (DENNETT, 2006). Nela, Hume debruça sobre os principais aspectos que envolvem as crenças religiosas, sua origem, seus ritos, suas diferenças, seus efeitos e utilidades.

Este artigo resulta de uma comunicação proferida por nós, na qual articulamos o interesse na obra de Hume com o interesse no fenômeno religioso de modo geral.

\footnotetext{
* Mestrando em Filosofia pela Universidade Federal de Minas Gerais (UFMG). Graduado em Filosofia pela Faculdade Jesuíta de Filosofia e Teologia (FAJE). E-mail: crysman1 @ hotmail.com.

** Graduando em Filosofia pela Faculdade Jesuíta de Filosofia e Teologia (FAJE). E-mail: cfdamasceno0191@gmail.com.

*** Graduanda em Filosofia pela Faculdade Jesuíta de Filosofia e Teologia (FAJE). E-mail: andrezacdamasceno@gmail.com.

"Será referido no corpo do texto como simplesmente "D".

2 Daqui em diante será citada como "NHR".
} 


\section{OS PROBLEMAS EPISTEMOLÓGICOS DO FENÔMENO RELIGIOSO}

Hume é, sem dúvida, um precursor dos atuais psicólogos cognitivos da religião. A lista dos seus herdeiros é excepcionalmente extensa. Daniel Dennett (2006, p. 27) afirma que Hume "foi seu herói intelectual". Hume pretende analisar as crenças religiosas e a história das religiões no intuito de apontar o que se mostra necessário e o que se mostra contingente em face da psicologia humana, salientando as suas causas para esses tipos de crenças sob uma perspectiva puramente naturalista. O que torna a análise humiana algo inovador consiste na sua explicação do fenômeno religioso que renuncia ao emprego de premissas a priori, bem como explicações dotadas de pressupostos metafísicos e/ou transcendentais. A NHR foi redigida na tentativa de Hume implantar seu ceticismo "contra a religião revelada [...] e a absoluta incapacidade da teologia de fundamentar os princípios religiosos tradicionais ou a moralidade" (WEBB, 1991, p. 142).

Segundo Hume duas interrogações fundamentais devem nortear os estudos acerca das religiões. A primeira interrogação diz respeito ao fundamento racional da religião em questão, enquanto a segunda corresponde à origem do fenômeno religioso na natureza humana.

A resposta concedida à primeira questão repousa no argumento do desígnio, isto é, dada a regularidade causal da natureza é possível inferir a presença de um artífice inteligente, responsável por criar, organizar e manter tal regularidade ${ }^{3}$. Nesse sentido, Hume não estaria se contrapondo aos argumentos vigentes da teologia racional de seu tempo. Ao que parece, Hume optou por manter o argumento do desígnio em NHR intacto tendo em vista livrar a si próprio de sofrer perseguição e condenação por heresia

\footnotetext{
${ }^{3} \mathrm{O}$ argumento do desígnio funciona, por analogia, da seguinte maneira: dado o ajuste harmônico entre meios e fins ou causa e efeito nas obras da natureza, podemos extrair daí a existência de uma inteligência divina, uma causa primeira. Esse argumento encontra-se reordenado sob os contornos do argumento ontológico e cosmológico, respectivamente elaborados por Santo Anselmo e Santo Tomás de Aquino. O argumento do desígnio - com suas causas finais e suas questões de analogia, comparação - acomoda as entidades imantes no mundo, sendo diretamente responsáveis por gerar a paz e o sossego. Por ser um argumento a posteriori foi aceito e admirado por grande parte dos autores de cunho empirista. $\mathrm{O}$ argumento do desígnio é a expressão da vontade de Deus no mundo onde tudo na natureza se reproduz com perfeição, e cada atributo contém um propósito teleológico que carrega impressa a marca de Deus. Para refutarmos o argumento do desígnio se faz necessário que afirmemos que esses tais assuntos possuem seu correspondente totalmente fora do alcance do entendimento humano, demonstrando que as nossas concepções de verdade/falsidade não possuem correspondente algum com os juízos e atributos de cunho divinos.
} 
pelo proselitismo evangélico ${ }^{4}$. Contudo, ele considera que a segunda pergunta, ou seja, a que indaga sobre a origem das crenças religiosas, é um problema sem resposta definitiva.

O lastro argumentativo de Hume envolve a rejeição da primeira pergunta, uma vez que este endossa que as crenças religiosas são irracionais e, por conseguinte, as tentativas de articulação de uma base racional das doutrinas religiosas são consideradas as exceções que fogem da regra.

\section{NATURALISMO}

Hume distingue na psicologia humana dois princípios: o primário e o secundário. Estão alojados entre os princípios primários os instintos naturais - que se entrelaçam ao instinto de sobrevivência como, por exemplo, o amor-próprio, o amor pelos filhos, a gratidão e o ressentimento. Os primeiros princípios são universais e invariáveis, pois são constatados em qualquer tempo e lugar, ao passo que os segundos princípios são adquiridos e apresentam mudanças ao longo das épocas e em determinados lugares (HUME, 2005, p. 21-22).

Em sua opinião, a religião se encontra incluída no grupo dos princípios secundários, porque a crença religiosa envolve um contraste de crenças e compromissos morais que são incrivelmente capazes de variar de homem a homem, a ponto de tais homens discordarem sobre os atributos da entidade a que dirigem o seu louvor. Disso decorre que os sentimentos e as crenças religiosas não participam dos princípios gerais e absolutos da natureza humana.

A argumentação racional que mencionamos consiste numa construção elaborada no intuito de oferecer uma resposta, transcrita em termos lógicos ou dedutivos, acerca

\footnotetext{
${ }^{4}$ Aqui o leitor de maior contato com os textos humianos irá notar uma contradição explícita, sobretudo em D, visto que nele Hume ataca o argumento do desígnio e rechaça categoricamente as provas racionais da existência de Deus. Os estudiosos de Hume, porém, supõem que "a fim de extravasar seu ceticismo religioso sem se ver acusado de blasfêmia, Hume adotou vários estratagemas tradicionais e empregou alguns de sua autoria" (NOXON, 1973, p. 173). No decorrer do texto, Hume (2005, p. 29) irá mostrar que o politeísmo era a religião primitiva. Somente depois os homens aderiram a formas monoteístas, derivadas obviamente de uma matriz politeísta. Outro estratagema retórico convenientemente utilizado por Hume se vincula a sua censura ao politeísmo, que ele considera como uma religiosidade animista e, portanto, irracional. Em um dos trechos, lemos: "tornar-se-á evidente que os deuses de todos os politeístas não valem mais que os duendes e as fadas de nossos ancestrais, e merecem bem pouca devoção ou veneração" (HUME, 2005, p. 44). Sendo assim, pelo menos nesse texto, ele foi capaz de se esquivar com sutileza de eventuais problemas com as autoridades cristãs, que professam um ato de fé monoteísta. O que não o impediu, porém, de dirigir no mesmo texto críticas ao monoteísmo, afirmando que seja "construída sobre princípios irracionais e supersticiosos" (p. 61).
} 
das bases epistemológicas da religião. Contudo, o homem religioso comum ${ }^{5}$ nem sequer exige a exposição de cadeias causais para oferecer uma justificava de sua crença. Para ele, a religião tem sua importância na vida privada, a fim de evitar o mal, e manter a ordem e a paz. Hume (2005, p. 59-60) se pronuncia:

\begin{abstract}
Ainda hoje na Europa, se perguntássemos a um homem do povo por que ele crê em um criador do mundo onipotente, ele jamais mencionaria a beleza das causas finais, que ele ignora totalmente; também não estenderia a mão para nos convidar a contemplar a flexibilidade e variedade das articulações de seus dedos, da curvatura uniforme de todos eles, do equilíbrio que mantém o polegar, das partes delicadas e carnosas da palma e de todas as outras circunstâncias que tornam tal membro apto para a função a qual foi destinado. Ele está acostumado a todas essas coisas há muito tempo e as olha com despreocupação e indiferença. Falará da morte repentina e inesperada de alguém, da queda e contusão de um outro, da seca extrema de tal estação ou do frio e das chuvas de outra. Atribui tudo isso à intervenção imediata da providência, e esses mesmos eventos que, para um bom entendedor, constituem os principais obstáculos ao reconhecimento de uma inteligência suprema, são para ele os únicos argumentos em favor dela.
\end{abstract}

Por "bom entendedor" Hume se referia aos intelectuais que eram obrigados a ter que advogar em favor da bondade da intervenção divina diante dos males da natureza, da guerra, da fome, entre outras maldades que assombravam todos os homens. O homem religioso comum não mantém a sua fé com base em argumentos complexos e racionais meticulosamente elaborados. Conforme Mark Webb (1991, p. 148) convenientemente sublinha, "a sociedade primitiva não precisava de um Newton para chamar atenção de alguns para algum 'plano consistente' na natureza".

Como a crença religiosa não exibe ou requer fundamento racional, a devoção religiosa é provocada pelo instinto natural de autopreservação que se encontra presente em todos os seres humanos. Ou seja, as razões que esse homem poderia vir a oferecer para sustentar a razoabilidade de sua fé não são dadas pelo mundo externo, como recorrem os autores das "provas racionais".

Do ponto de vista do naturalismo humiano, a religião contém uma grande utilidade e ocupa uma parte central da psicologia. Dennett nos esclarece bastante sobre o projeto levado a cabo por Hume:

Hume queria considerar se havia um bom motivo - qualquer razão científica, poderíamos dizer - para acreditar em Deus. A religião natural, para Hume,

\footnotetext{
${ }^{5}$ Em seu próprio vocabulário Hume usa frequentemente a palavra "vulgar" (convenientemente traduzido na versão brasileira como "homem do povo") para se referir aos homens comuns, isto é, àqueles que não fazem parte da elite intelectual, ou de pouca instrução.
} 
seria um credo que foi tão bem apoiado por evidências e argumentos como a teoria da gravitação de Newton, ou geometria plana. Ele contrastou isso com religião revelada, que dependia das revelações da experiência mística ou outros caminhos extra-científicos para a convicção. (DENNETT, 2006, p. 2627) ${ }^{6}$.

Para compreender a tese de Hume é preciso ter em mente que ele considera a crença religiosa sendo condicionada por um sentimento ou disposição psicológica, e não como um sistema coeso de ideias estabelecidas por raciocínio metódico. Assim, as crenças religiosas residem no terreno do sentimento, de modo que o sentimento religioso é despertado e está estreitamente entrelaçado com os instintos naturais. Isso significa que a crença endereçada à divindade não se encontra embutida a priori na mente. Ela é, bem como as características atribuídas à divindade, ensinada pela cultura.

O naturalismo de Hume perpassa pelo seu ceticismo. Para ele é vital perceber que os homens não são capazes de alcançar o conhecimento pleno de todos os fenômenos do mundo. Esse diagnóstico leva os homens a criarem superstições a fim de se manterem calmos e evitarem o desespero. O sentimento do desconhecido é relatado mediante as seguintes palavras:

\begin{abstract}
Estamos colocados neste mundo como em um grande teatro, onde as verdadeiras origens e causas de cada acontecimento nos estão inteiramente ocultas. Não temos sabedoria suficiente para prever os males que continuamente nos ameaçam, nem poder para evitá-los. Vivemos suspensos num perpétuo equilíbrio entre a vida e a morte, a saúde e a doença, a saciedade e o desejo, coisas que são distribuídas entre a espécie humana por causas secretas e desconhecidas, e que atuam frequentemente de forma inesperada, e sempre, inexplicável. (HUME, 2005, p. 35).
\end{abstract}

Ele sustenta que os homens precisam urgentemente de respostas no sentido de amenizar drasticamente as suas próprias crises existenciais. Do contrário, viveriam em estado de desespero e pânico.

Assim, o instinto de sobrevivência age em favor de nos provocar medo, anseios, dúvidas que são identificados por Hume na base das crenças religiosas da humanidade. Ele escreve:

As únicas paixões que podemos imaginar capazes de agir sobre tais homens incultos são as paixões ordinárias da vida humana, a ansiosa busca da

\footnotetext{
${ }^{6}$ Este trecho de Dennett retrata muito bem o quanto a doutrina do método experimental das ciências empíricas, tão recorrente em outros textos de Hume, é compatível com o tipo de doutrina esboçada em NHR. Para maiores informações e comparações, seria interessante consultar o Tratado da Natureza humana (HUME, 2001) e o artigo de Crysman Dutra denominado A ciência da natureza humana na filosofia de Hume (2018).
} 
felicidade, o temor de calamidades futuras, o medo da morte, a sede de vingança, a fome e outras necessidades. Agitados por esperanças e medos dessa natureza, e sobretudo pelos últimos, os homens examinam com uma trêmula curiosidade o curso das causas futuras, e analisam os diversos e contraditórios acontecimentos da vida humana. E nesse cenário desordenado, com os olhos ainda mais desordenados e maravilhados, eles veem os primeiros sinais obscuros da divindade. (HUME, 2005, p. 32-33).

Porém, todo acidente funesto nos desperta e incita a efetuar investigações sobre seus princípios e origem. Surgem apreensões em relação ao futuro, e o espírito, em virtude da desconfiança, do terror e da melancolia, recorre a todos os métodos suscetíveis de satisfazer os poderes secretos e inteligentes, dos quais, pensamos nós, nosso destino depende inteiramente (HUME, 2005, p. 39-40).

\section{CETICISMO}

A análise de Hume acerca do desenvolvimento da religião natural se sucede por aplicação de um princípio empirista, no qual todo o conhecimento é derivado da experiência. Em seu D, o ceticismo juntamente com o empirismo constituem os elementos primordiais situados na construção da crítica humiana. Já vimos que ele introduz a fé religiosa ao plano do mistério, da dúvida e do medo, isso fica reforçado na passagem em que ele diz que: "somos como forasteiros em uma terra estranha, aos quais tudo parece suspeito e que permanentemente correm o risco de transgredir as leis e os costumes das pessoas com quem convivem e se relacionam.” (HUME, 1992, p. 17).

Mediante as dúvidas céticas, Hume claramente põe em xeque a posição segundo a qual há um fundamento racional para afirmar crença em entidades que ultrapassam o âmbito da experiência cotidiana. Assim, em tom de comando, ele afirma: "Tornemo-nos plenamente conscientes da debilidade, cegueira e estreiteza da razão humana." (HUME, 1992, p. 11). Aqui fica clara a sua veia cética, indicado sobretudo pelo fato da razão, por si só, não conseguir gerar dados ou fórmulas seguras o bastante para adquirir uma sólida compreensão acerca de propriedades, objetos e entidades que se apresentam de modo tão distante da experiência humana.

Dessa forma, o que nos sobra é apenas a suspensão do juízo - uma prescrição cética. Portanto é impossível conceber, em termos estritamente racionais, o conceito e os atributos de Deus que a religião popular nos oferece, e nem tampouco nos cabe negálo com uma larga margem de segurança. Nesse sentido, a probabilidade da existência 
divina ou a sua improbabilidade é supostamente remota para os mecanismos cognitivos falíveis e limitados dos seres humanos ${ }^{7}$. Como nos diz o filósofo:

Quando nossas especulações se restringem aos negócios, à moral, ou à política, podemos a cada instante apelar para o senso comum e para a experiência, que fortalecem nossas conclusões filosóficas e removem (em parte, ao menos) a desconfiança que acertadamente experimentamos frente a todo raciocínio demasiado sutil e refinado. No caso dos raciocínios teológicos, contudo, não dispomos dessa vantagem; e, ao mesmo tempo, estamos lidando com objetos que são, sem dúvida, excessivamente vastos para que possamos apreendê-los, e que, de todos, são os que mais esforço exigem para que se tornem familiares à nossa compreensão. (HUME, 1992, p. 17).

O texto de D foi redigido com a intenção de defrontar o argumento do desígnio ${ }^{8}$ que postula um agente responsável por colocar em curso, de modo harmônico, as coisas da natureza. Hume pretende ameaçar o poder dessa argumentação expondo as suas fragilidades. Além disso, é importante notar que Hume parece a todo instante estar optando por uma posição neutra e agnóstica em relação à concepção tradicional, isto é, em relação à religião revelada. Com efeito, é nítido que não há como demonstrar ou efetuar um prognóstico sobre a existência ou inexistência de Deus a partir das evidências empíricas disponíveis. Até porque para que se possa vir a afirmar que Deus, de fato, é um ser que possui em sua existência uma razão necessária para existir, é também preciso conhecer sobre a sua natureza ontológica - o que por si só não é possível, posto ser a nossa compreensão ou nossas faculdades limitadas demais para que possamos conhecer a natureza de Deus e, por conseguinte, dar a ela uma razão de ser necessária.

Os que insistem em extrair conclusões necessárias para provar a existência de Deus derivadas desse tipo de raciocínio estão fazendo uma busca de antemão fracassada e irracional. É por esse motivo que Hume encara as especulações metafísicas e místicas sob um olhar depreciativo, pois, de acordo com Hume, elas geram sofismas e são irrelevantes para o conhecimento de fatos empíricos. Uma vez que a "nossa experiência limitada não constitui um padrão aceitável para julgar sobre a extensão ilimitada da

\footnotetext{
${ }^{7}$ Ao que nos parece, a posição mais aceitável e viável para o ceticismo de Hume seria o agnosticismo religioso. Embora não tenhamos elementos suficientes para realizar uma avaliação séria e propiciar um diagnóstico acurado a esse respeito. $\mathrm{Na}$ terminologia conceitual, é justamente este tipo de postura que queremos defender, pois agnosticismo é, antes de tudo, a negação ou ausência do conhecimento. Paul Russell (2008) discute com maior riqueza de detalhes a crença religiosa de Hume em seu livro The riddle of Hume's treatise (p. 279-289).

${ }^{8} \mathrm{Na}$ nota 6 resumimos os aspectos centrais do argumento do desígnio. Não cremos que seja necessário dilatar a explicação no corpo do texto.
} 
Natureza", portanto, deve-se "[...] reconhecer a absoluta incompreensibilidade da Natureza Divina” (HUME, 1992, p. 84).

Desse modo, o que fica explícito e o que deve ser levado em conta é a admissão de que todos os sistemas religiosos estão expostos a grandes e insuperáveis dificuldades, como nos chama atenção Hume (1992, p. 112):

[...] todos eles, em conjunto, proporcionam um triunfo completo ao cético, que lhes diz que nenhum sistema deve ser adotado com relação a esses tópicos; e isto pela simples razão de que não se deve jamais dar assentimento a um absurdo, em qualquer assunto que seja.

Assim sendo, Hume mostrou que há uma ampla dificuldade para a produção consistente de uma justificativa racional que dê conta de satisfazer uma busca persistente para o fundamento lógico da religião. A experiência nos mostra que os assuntos concernentes à religião possuem uma limitação intrínseca e quando profere seus juízos não dá conta de abarcar tudo de modo puramente dedutivo e apriorístico, ou então, as suas autoridades clericais apelam para recursos ad hominem (GUIMARÃES, 2013). Nesse caso, o melhor a se fazer é optar pelo ceticismo filosófico mediante a suspensão do juízo. À fé cabe se ocupar com as coisas religiosas e supersticiosas, e não à razão. Mesmo porque, tais assuntos, se investigados à luz da razão, não progridem de forma alguma.

No corolário geral de NHR, onde Hume expõe mais detidamente a sua doutrina, ele conclui:

É tudo uma incógnita, um enigma, um mistério inexplicável. O único resultado de nossas investigações mais meticulosas sobre esse assunto parece ser a dúvida, a incerteza e a suspensão do juízo. Mas tal é a fraqueza da razão humana e tão é irresistível contágio da opinião que dificilmente podemos manter essa dúvida deliberada. (HUME, 2005, p. 126).

Por fim, Hume se mantém numa posição neutra. De modo plenamente compatível com o seu ceticismo, deixando assim diversas perguntas sem respostas definitivas, relegadas ao plano do "mistério inexplicável”, pois Hume está consciente de que para algumas perguntas é impossível fornecer respostas imunes à dúvida. Resta somente especular sobre esses enigmas, cujas verdades são inacessíveis ao entendimento humano. 


\section{CONCLUSÃO}

No período em que Hume viveu a crença religiosa era explicada em termos metafísicos e transcendentais, como algo que constituía essencialmente a natureza humana. Hume, contudo, se afastou dessa explicação. Devido à explícita heterodoxia dos seus escritos, Hume sofreu repressão e jamais conseguiu uma cátedra na Universidade de Edimburgo, apesar de ser amigo do renomado filósofo Adam Smith (MONTEIRO, 2009, p. 166).

Em outras palavras Hume está afirmando que o homem não é, por natureza, portador de crenças religiosas. Por outro lado, as crenças religiosas são um subproduto do instinto de sobrevivência humano e, portanto, acompanham a história humana, desde a sua manifestação através do politeísmo.

\section{REFERÊNCIAS}

DENNETT, Daniel. Breaking the spell: religion as a natural phenomenon. Penguin Books, 2006.

DUTRA, Crysman. A ciência da natureza humana na filosofia de Hume. Contextura, Belo Horizonte, v. 10, n. 12, 2018, p. 13-20.

GUIMARÃES, Lívia. Retórica anticética nos Diálogos sobre a religião natural de Hume. Natureza humana, 2013, p. 174-193.

https://www.google.com/search?q=GUIMAR\%C3\%83ES\%2C+L\%C3\%ADvia.+Ret\%C3\%B3rica+a ntic\%C3\%A9tica+nos+Di\%C3\%A1logos+sobre+a+religi\%C3\%A3o+natural+de+Hume.\&oq=GUIM AR\%C3\%83ES\%2C+L\%C3\%ADvia.+Ret\%C3\%B3rica+antic\%C3\%A9tica+nos+Di\%C3\%A1logos+sob re+a+religi\%C3\%A3o+natural+de+Hume.\&aqs=chrome..69i57.445j0j7\&sourceid=chrome\&ie=U $\underline{\mathrm{TF}-8}$

HUME, David. Diálogos sobre a religião natural. São Paulo: Martins Fontes, 1992.

HUME, David. História natural da religião. São Paulo: UNESP, 2005.

HUME, David. Tratado da natureza humana. São Paulo: UNESP, 2001.

MONTEIRO, João Paulo. Hume e a epistemologia. São Paulo: Editora UNESP; Discurso Editorial, 2009.

NOXON, James. Hume's philosophical development. Oxford University Press, 1973.

RUSSELL, Paul. The riddle of Hume's treatise: Skepticism, Naturalism, and Irreligion. Oxford University Press, 2008. 
WEBB, Mark. The argument of "The natural history". Hume Studies, v. 17, n. 2, p. 141-160, 1991. 